\title{
Changes in Trends During COVID-19 Pandemic: A Focus on Tourism and Plastic Industries
}

\author{
Andrea Pontrandolfo ${ }^{1}$, Annarita Paiano ${ }^{2}$, Tiziana Crovella ${ }^{3}$ and Miraj Ahmed \\ Bhuiyan $^{4}$ \\ ${ }^{1) 233)}$ University of Bari Aldo Moro, Department of Economics, Management and \\ Business Law, Bari, Italy. \\ 4) Guangdong University of Finance \& Economics, Guangzhou, China. \\ E-mail: andrea.pontrandolfo@uniba.it; E-mail: \\ annarita.paiano@uniba.it E-mail: tiziana.crovella@uniba.it; E- \\ mail: ahmed.miraz@qq.com
}

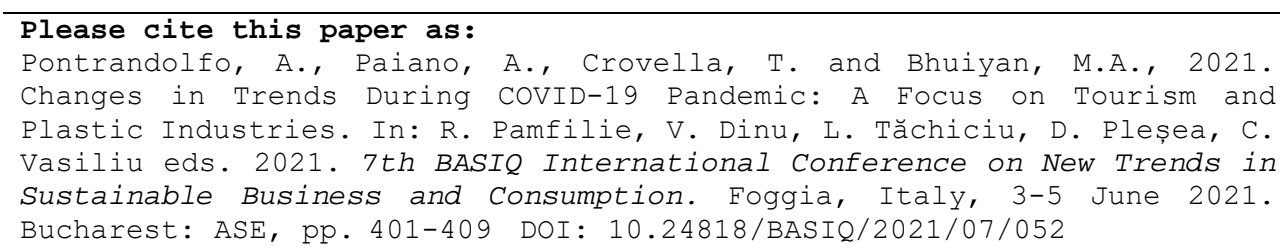

\begin{abstract}
Since February 2020, the Covid-19 pandemic has created a significant disruption of global markets with important effects on the personal, social, economic and professional lives of the people. The uncertainty and fear of the society, together with the severe limitations imposed on a global level, has made tourism one of the sectors most affected by the crisis, contributing significantly to the decrease in the consumption of products packaged in Polyethylene Terephthalate (PET), which is widely used in the tourism-related activities. These issues, jointly with the heavy reduction of industrial production, led to an inevitable collapse in oil demand, which made virgin plastics cheaper than recycled ones.

The purpose of the paper is to evaluate the impact of the Covid-19 pandemic on the tourism sector, examining the consequences of this impact on the consumption of PET and R-PET (Recycled PET).

The research methodology firstly involves an investigation of the scientific literature and data sector, comparing 2019 and 2020, in order to highlight the significant issues and changes, both in international arrivals and environmental effects, occurred in the global tourism during the pandemic period. Secondly, by analysing the trends of oil prices, an economic focus on PET and R-PET industry was carried out.
\end{abstract}

A strong correlation was found between the collapse of the tourism market, a decrease in the price of oil, and consequently an increase in the use of virgin PET. This paper adds new insights on the distortive effects on the economics and environment, due to pandemic.

Finally, the public health crisis represents a great opportunity to consider tourism holistically in terms of its effects on the environment and climate, but also on consumer and producer behaviours.

\section{Keywords}

Covid-19, Tourism, Plastics, Oil price.

DOI: 10.24818/BASIQ/2021/07/052 


\section{Introduction}

The pandemic has raised concern on various issues. Particularly, there is a strong apprehension about the personal and psychological aspect of the population, due to economic factors and health, but also to the environmental issues.

Among the most important economic effects that occurred following the world crisis associated with Covid- 19 was the breakdown of tourist flows (Škare, Soriano and Porada-Rochoń, 2021). Despite the first effects have already emerged in February 2020, the collapse of tourism activities has occurred at the beginning of March, because the social distancing measures as well as national and international measures adopted to prevent the virus spread, began.

Nowadays the return to travelling seems to be a still remote possibility in these phases of recovery from the crisis caused by the coronavirus. The security measures implemented worldwide, such as confinement and various forms of social distancing, with the correct safety precautions, are beginning to be relaxed and tourism will play a decisive role in the economy's recovery. Moreover, it will also provide important information on the state of health and safety of the different countries. Obviously, the revival of tourism will have different timing in various parts of the world, so it is difficult to predict how domestic tourism will recover, indeed, while some nations may get back rather quickly, others may struggle and need more time (Zhang, et al., 2021).

The uncertainty that characterized 2020 led to a significant reduction in holidays, a drastic reduction in catering and air travel, the cancellation of numerous sporting, cultural, musical and theatrical events. All these activities have contributed significantly to the decrease in the consumption of products packaged in Polyethylene Terephthalate. PET is widely used in all tourism-related activities because it is the most common plastic to package bottled water, soft drinks and food. Despite the sharp drop in PET packaging in all activities related to the tourism sector, plastics have sharply increased by the emergency linked to the Coronavirus, but also for food safety and compliance with high-quality standards.

During the pandemic, the closure of production plants and the collapse of transports caused a significant reduction in the global demand for oil (Bourghelle, Jawadi and Rozin, 2021). Consequently, the collapse in the price of crude oil has made it more profitable to produce virgin plastics from fossil resources rather than using recycled plastics.

To help raise awareness of the impact generated by Covid-19 on production and consumption, this paper analysed the consequences of the Covid-19 impact on tourism and plastics markets, with a focus on polyethylene terephthalate, one of the most consumed plastic materials.

\section{Review of the scientific literature}

In the last year, the scientific publications regarding the effects of Covid-19 on tourism have been numerous (Persson-Fischer and Liu, 2021).

The objective of the study by Collins-Kreiner and Ram (2020) was to evaluate the impact that the pandemic has generated on the tourism system in different countries, but at the same time to analyse the national and global policies adopted to fight the crisis. The authors underlined that there are deep differences in the tourism industries of the different countries, and although it is very complex, common guidelines for the rehabilitation of the sector needed.

The Australian tourism sector was analysed by Pham et al. (2021); the authors stressed the relevance of tourism on the national GDP and the employment levels too, underlining that the effects of the reduction of tourism activities negatively affected many closely connected sectors, consequently, the increase of the Australian tourism allow the economic results of related industries to be increased. Wen et al. (2020) have elaborated key insights useful to create strategies for the entire tourism sector, to increase the confidence of tourists following the Covid-19 crisis. In their paper, the authors analysed the new trends, behaviours, and travel preferences of post-pandemic Chinese tourists. It emerged that slow tourism is highly appreciated, and tourists will prefer increasing the time spent in a single place preferring the quality of the experience rather than the number of places visited. 
Brizek, et al. (2021) focused on the economic consequences of the pandemic through the use of a survey to the South Carolina restaurant managers. The analysis revealed that, after around 60 days of restaurant closure, $25 \%$ of managers were unable to reopen their activities, confirming the suffering of the restaurant business.

In their article, Cavallo, Sacchi, and Carfora (2020) analysed the change in daily habits and the new needs of the Italian population due to new behaviours resulting from the pandemic. In addition, the authors examined the exponential growth of e-commerce, which in the lockdown period, allowed a significant increase in the familiarity of the population with new communication devices. Panzone, Larcom and She (2021) investigated the impact of the pandemic on the retail sector, highlighting significant losses for the catering sector, unlike supermarkets which increased their sales.

The air transport sector has been deeply affected by the pandemic. Many airlines are lobbying for government subsidies and aid. Other airlines have fired employees, so the unemployment rate against the related workforce would be 7\% $-13 \%$ (Sobieralski, 2020).

Sharma, Thomas and Paul (2021) propose a resilience-based framework composed of four key factors for the tourism sector to overcome the Covid-19 crisis. The authors identified four factors that need working together to make the entire sector resilient enough to deal with the crisis: government response, technology innovation, local belongingness, and consumer and employee confidence.

During the pandemic, the huge use of single-use plastic products inevitably increased the complexity of managing this waste. Vanapalli, et al. (2021) analysed the plastic waste sector by providing important recommendations for policymakers to avoid the increased use and consequent disposal of single-use plastics. Among the most important recommendations, there is certainly that of making citizens aware mainly during the school period, guaranteeing part of the education to environmental science. The issue of plastic during the pandemic was also discussed by Silva, et al. (2021). The authors highlighted the need to increase the studies and the use of biobased plastics to improve their environmental compatibility in a circular economy perspective. Furthermore, in their study, they stressed the importance of producer responsibility throughout the life cycle of plastic products in order to minimize plastic losses and pollution.

\section{Research methodology}

The research methodology involves an investigation of the scientific literature in order to highlight the significant issues and changes occurred during the period of health emergency. The analysis has undertaken according to the comparison between different years (2019 and 2020). Specifically, the collection and analysis of the global data allowed to assess the consequences of the Covid-19 pandemic on the tourism industry. Moreover, a further analysis was carried out through the study of the prices of PET and R-PET following the closures of the main consumer activities of bottles for beverages, water, food, such as universities, tourist attractions, restaurants, events of various kinds. In this regard, a further analysis on the relationship between the demand and supply of oil has been conducted. Finally, based on the change in the oil price during the pandemic crisis, the economic and environmental implications of the use of virgin raw materials instead of the use of recycled ones were analysed and referred to the first months of the pandemic.

\section{Results and discussion}

Effects of Covid-19 on the tourism industry

Starting from the first quarter of 2020 following the Covid-19 pandemic, the whole world has been characterized by significant travel restrictions which have strongly affected the tourist flows (Gössling, Scott and Hall, 2021). 

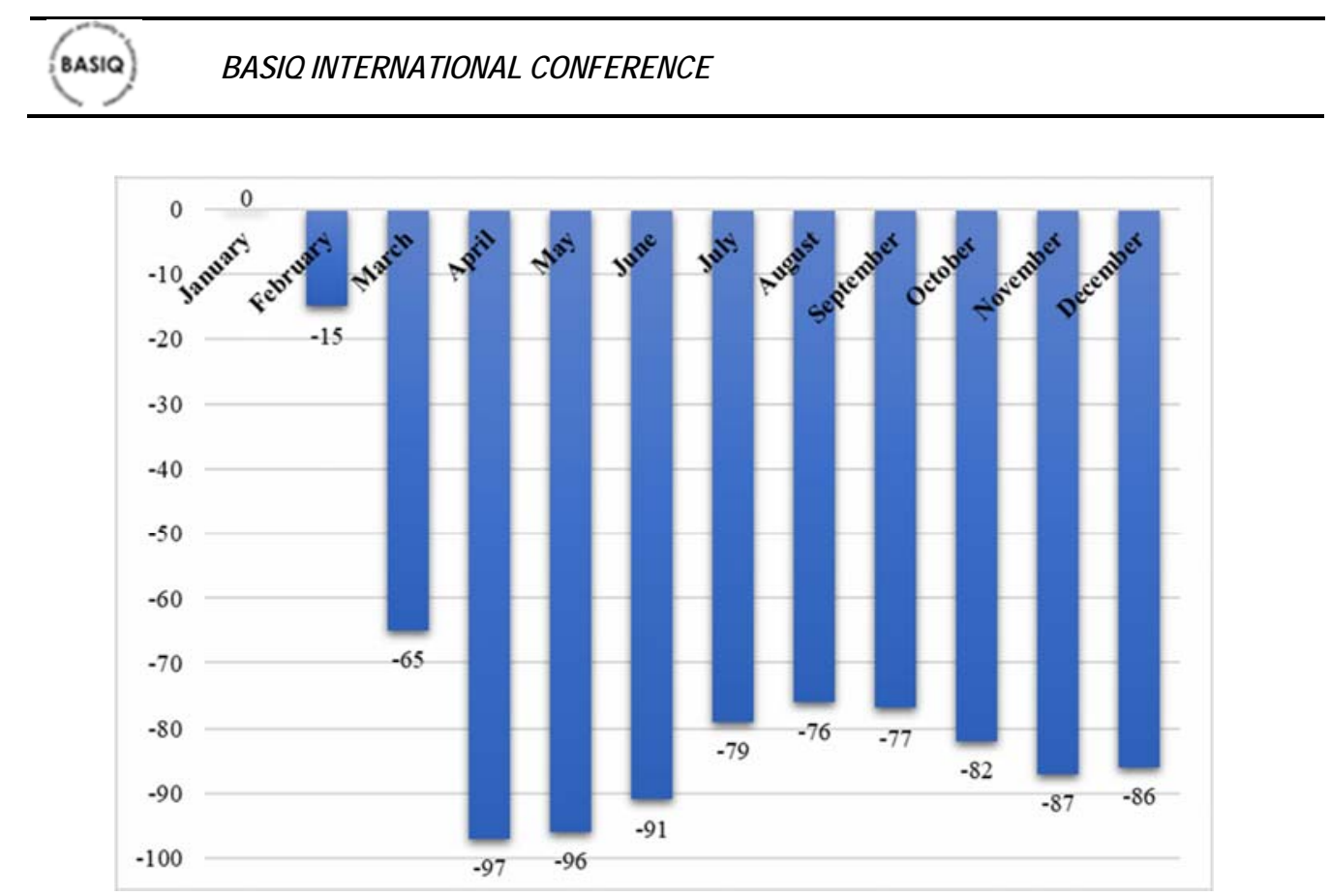

Figure no. 1. Global international tourist arrivals in 2020 compared with 2019

\section{Source: UNWTO, $2021 b$}

The tourism system has always been one of the pillars of the country's economy. A significant part of the national GDP is linked to tourism, with the involvement of many different sectors. According to Wang et al. 2020, pandemic is deeply influencing the development of the global economy and threatening the survival of businesses around the world. Tourism has always played an important role in the economic growth of a country: globally, it represents $10 \%$ of GDP (WTTC, 2020). It represents a strong accelerator both from an economic and social level; it creates job opportunities, increases productivity, encourages investments, allowing an improvement of the entire national context. According to the latest data from the UNWTO (United Nations World Tourism Organization, 2021a), due to the pandemic, international arrivals globally decreased by $73 \%$ compared to 2019 .

In Europe, the reduction by $70 \%$ in arrivals, compared to 2019 , resulted in the loss of 500 million tourists, while in Asia and the Pacific there was a decrease by $84 \%$ in arrivals, equal to 300 million fewer tourists. As shown in fig.no. 1, globally, the international arrivals in the year 2020 have drastically reduced in comparison with 2019. Only in the summer season, they have improved. The tourism figures during the pandemic were dramatic and, above all, due to the uncertainty of the current situation, few years need before international tourism could return to the levels of 2019.

\section{Environmental effects of Covid-19}

As noted by Lokhandwala and Gautam (2020), nature and the environment have certainly benefited from the shortage of industrial activities, road traffic and tourism.

Considering data reported by IEA (2020), due to reductions in oil, natural gas and coal during the first quarter of 2020, compared with the same period of 2019, the Global CO2 emissions decreased by over $5 \%$ particularly in the regions most affected by the initial and largest impacts of a pandemic such as China (-8\%) and the European Union (-8\%). In the same period, the global energy demand decreased by $3.8 \%$. Nagaj and Žuromskaite (2021) investigated the effect of the Covid-19 on the impact of tourism sector on the level of the Greenhouse Gas (GHG) emissions. The study focused on $10 \mathrm{EU}$ countries. The authors pointed out a positive correlation between the tourism sector development and the GHG emissions generated by this sector. Moreover, has been noted that, following a strong reduction in arrivals and in business turnover, as compared to 2019, GHG emissions in all European countries have fallen. In 2014 Katircioglu, Feridun, and Kilinc, investigated the long-term relationship between international tourism, energy consumption, and climate change in Cyprus. They observe that 
the negative environmental impact is not caused by all kinds of tourism activity, but overall, by international tourism.

One of the most important sources of GHG emission has been particularly affected by the crisis. The global demand for passenger transport significantly reduced due to national and international tourism travel restrictions. The Covid-19 pandemic has certainly generated a negative impact on the growth of the tourism industry, but, at the same time, it brought to a significant decreasing in energy consumption. (Chu et al., 2020). In the period March-April 2020, compared to the previous year, there was a $90 \%$ decrease in flights operated (European Commission, 2020); consequently, these figures pointed out a significant decline in GHG emissions from the aviation industry in 2020.

The positive effects of tourism reduction in one of the most visited cities of the world have been analysed by Braga et al. (2020). Thanks to satellite imagery the authors, comparing data of 2019 and 2020 , stressed the significant improvement of water quality in the Venice canals and the lagoon.

Moreover, one of the most short-term positive effects of lockdowns has been the remarkable improvement in air quality. Especially in the world's most polluted cities the concentrations of $\mathrm{NO}_{2}$, mainly due to the road transport reductions, have been reduced in many countries, where lockdown measures were implemented (EEA, 2021).

Muhammad, Long, and Salman (2020) based on data from European Space Agency (ESA) and National Aeronautics and Space Administration (NASA) highlighted how, in the countries most affected by Covid- 19 such as Wuhan, Italy, Spain, USA, France, during the period between January and March 2020, pollution has reduced up to $30 \%$, due to the suspension of many economic activities.

Pandemic has certainly beneficed nature and the environment by reducing energy consumption, pollution, and air and water quality; on the other hand, it has generated a sharp increase in waste, especially plastic waste generated by the personal protective equipment needed during pandemic.

The desperate fight to limit the spread of the virus led to taking a break from the recent progress made in sustainability and waste management. In 2018, the European Union had banned the ten most popular single- use plastic products by 2021 , but due to the current crisis, in many cases, the fear of spreading the virus forced policymakers to a step back, indeed, some countries have withdrawn the bans on the use of single- use plastic and restricted the use of reusable products.

This situation has dangerous long-term repercussions on the environment, in addition there is the real risk of losing years of progress in reducing single-use plastics and encouraging the use of more recyclable plastics.

\section{Effects of Covid-19 on the packaging and oil prices. A focus on PET supply chain}

The restrictions worldwide imposed, have forced the suspension for a long period of a wide range of tourism-related activities, such as travel, transport, accommodation, catering, cultural activities, festivals, events and concerts. Notwithstanding the strong standstill of all these activities, which generally have a very high consumption of materials and great environmental impacts in terms of waste (e.g., restaurants) and consumption of resources, the use of some materials such as plastic, did not decrease during the pandemic. Indeed, we have seen a reduction in the consumption of bottles and plastic packaging commonly used in restaurants and bars, but at the same time, a constant increase of a wide range of disposable plastic products related to the fight against the pandemic.

There is a strong relationship between PET packaging and tourism, as travelers typically avoid tap water when abroad, with a high increase in bottled water and soft drinks sales in holiday destinations. Tourism is a key sector in the production of plastic waste; it has been estimated that 200 million tourists who visit the Mediterranean every year, generate a $40 \%$ increase in summer plastic pollution (WWF, 2018). Moreover, in 2016, 53,000 tons of plastic waste were dispersed in the Mediterranean Sea, for this reason, the Italian coastal areas, there are among the highest concentrations of plastic waste largely due to invasions by tourists (WWF, 2019).

The impact on the packaging market during pandemic, was not homogeneous among different areas of applications. Some packaging uses, such as food and health, performed relatively well, whereas others like the packaging for non-essential goods suffered large economic losses due to the pandemic. The 
global shock has led within the global plastics industry a strong uncertainty, due to the disruptions in raw material supply and distribution logistics. In this context, the market had to adapt very quickly to satisfy changing demand models.

In addition to the reduction of plastic consumption in the tourism industry, the stop of this sector has brought to a strongly reduction in the fuel consumption due to the cancelled flights, cruises and travels. These issues, jointly to the heavy reduction of the industrial production, led to an inevitable collapse in oil demand. Since the price of oil affects the entire petrochemical chain including thermoplastics, the consumption of virgin plastic products has grown dramatically (Adyel, 2020) due to the collapse in oil prices. Conversely, the use of recycled plastic decreased since it became more expensive.

Taking into account the close relationship between the price of oil and the price of virgin plastic products, this paper analysed the consequences in the R-PET sector during the pandemic. The collapse in oil prices during the first months of 2020 led to a reduction in the prices of virgin oil-derived plastics, exerting strong pressure on the prices of recycled plastics. The price of oil went from \$ 72 in May 2019 to $\$ 20$ in April 2020 (fig.no. 2), making petroleum-based virgin materials, such as plastics, more attractive than their sustainable and more expensive alternatives.

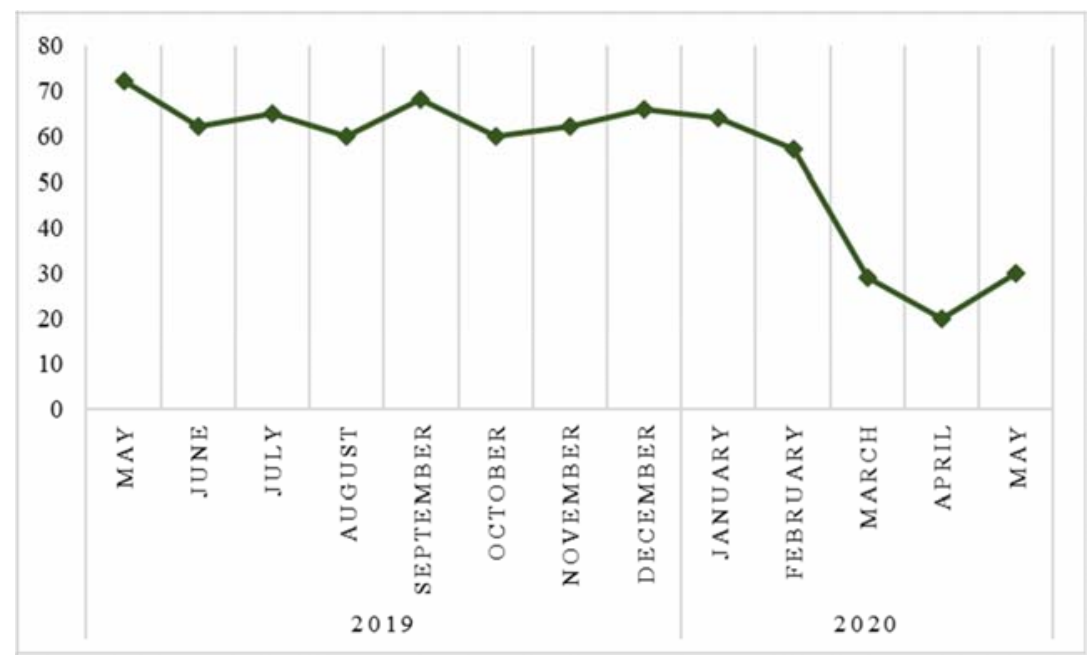

Figure no. 2. Oil price trend during pandemic (\$ per barrel)

Source: Il Sole 24 Ore, 2021

During a period in which the attention on low environmental impact materials - especially recycled ones - was decisively taking off, due to the pandemic the R-PET market suffered a strong slowdown. The prices of recycled plastics are no longer competitive and profitable, and inevitably many companies in the sector have been excluded from the market.

The demand for R-PET has significantly fallen, mainly due to the availability of significantly cheaper virgin PET on the market. The decrease in demand for recycled material has made collection, storage and delivery more complex; moreover, the closure of a lot of manufacturing plants, and the simultaneous collapse in the price of virgin raw materials, have encouraged some companies to quit the use of RPET.

The fig.no. 3 shows the trend in the price of virgin PET and R-PET during the initial period of the pandemic. As we can see from the figure, the price of virgin PET and R-PET in May 2019 were very similar, with a slight convenience of recycled material. The price of R-PET has been fairly constant over time, unlike virgin PET; compared to the same period of the previous year, the price of virgin PET decreased by roughly $34 \%$, whereas R-PET has been dropped about $4 \%$. 


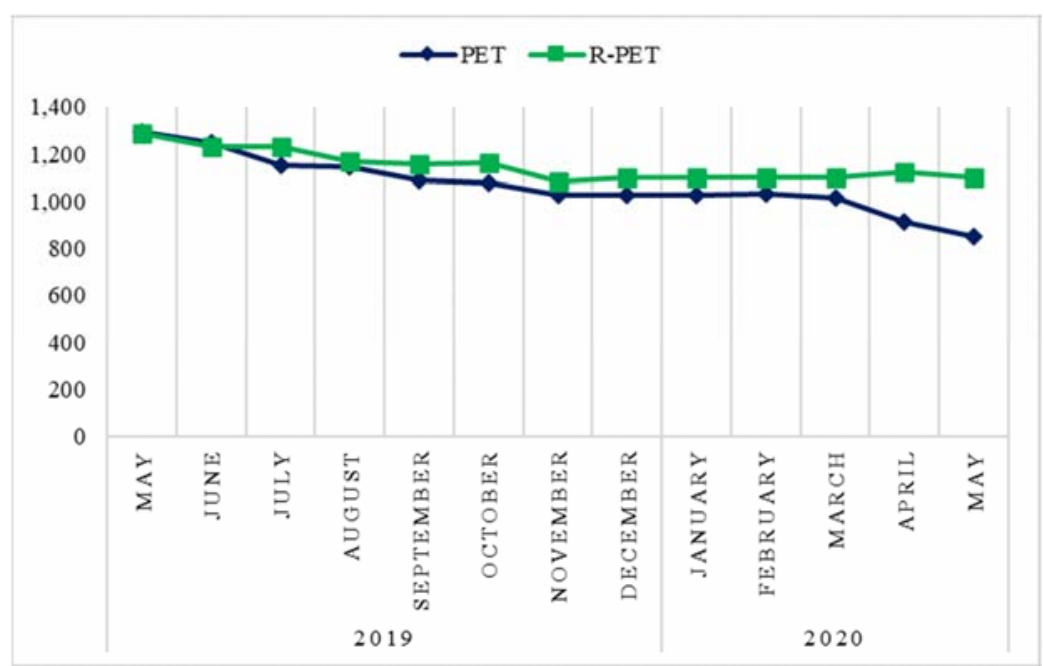

Figure no. 3. PET and R-PET price trend during pandemic (\$/ton)

Source: ICIS, 2020

Additionally, the difference between the two prices needs to be investigated. Starting from the first months of the pandemic, and following the collapse in the price of oil, the price difference between the two materials has significantly increased. In particular, initially, the choice between virgin PET and RPET was not strongly affected by the price. Indeed, up to March 2020, the average gap between the prices of the two materials was about \$53.80/ton, whereas, between April and May the gap has grown significantly to roughly $\$ 230.76 /$ ton, making the purchase of virgin PET significantly more advantageous than R-PET. The price issue is not the only significant variable, indeed, many producers worried about the difficulties in the procurement of recycled material, have turned to virgin raw materials for the reliability of the supply chain.

Consequently, following the low availability of R-PET, due to the closures of numerous production plants for recycled plastics, many companies involved in the last years in the transition process from PET to R- PET, have been forced to slow down this process. Additionally, due to the lack of tourism and sport, music, cultural events, and limitation for the Horeca sector in 2021, which heavily affected the consumption of bottled beverages, a limited quantity of raw materials for PET recycling occurring.

\section{Conclusions}

The present research assessed the impact of the Covid-19 pandemic on the tourism sector, evaluating the influences on packaging sector and the fall in the oil prices. Particularly, it provided new insights on the distortive effects due to the pandemic on the economics and environment, focusing on tourism and plastics sectors.

As we know, the tourism industry includes many closely related activities such as transport, catering, hotels, musical events, etc. In 2020, the worldwide price of oil was strongly affected by the Covid-19; in this context, as result of the collapse of all these activities has led to a drastic reduction of commonly used PET products, such as beverage bottles and food packaging. The oil price affects the entire petrochemical chain and especially thermoplastics. This situation has generated high uncertainty in the recycled plastics market. In addition to the economic convenience of purchasing virgin PET compared to R-PET, the risks in the supply of R-PET encouraged many producers to use virgin material instead of recycled one. To prevent these issues will recur in the future, in order to stimulate the use of recycled materials in a circular economy perspective, the need for important targeted measures by policymakers through incentive policies will be crucial.

Since currently, available data is limited, due to the continuous changing of the health crisis, the authors' future perspective aims to increase knowledge about the effect it had on the consumption of virgin and recycled PET by companies, also quantifying the environmental impacts generated by the pandemic. 


\section{References}

Adyel, T.M., 2020. Accumulation of plastic waste during COVID-19. Science, 369(6509), pp.13141315.

Bourghelle, D., Jawadi, F. and Rozin, P., 2021. Oil Price Volatility in the context of Covid-19. International Economics, In Press.

Braga, F., Scarpa, G.M., Brando, V.E., Manfè, G. and Zaggia, L., 2020. COVID-19 lockdown measures reveal human impact on water transparency in the Venice Lagoon. Science of The Total Environment, 736, Article number: 139612.

Brizek, M.G., Frash, R.E., McLeod, B.M. and Patience, M.O., 2021. Independent restaurant operator perspectives in the wake of the COVID-19 pandemic. International Journal of Hospitality Management, 93, Article number: 102766.

Cavallo, C., Sacchi, G. and Carfora, V. 2020. Resilience effects in food consumption behaviour at the time of Covid-19: perspectives from Italy. Heliyon, 6(12), Article number: e05676.

Chu, W., Calise, F., Duić, N., Østergaard, P.A., Vicidomini, M. and Wang, Q. 2020. Recent Advances in Technology, Strategy and Application of Sustainable Energy Systems. Energies, 13(19), Article number: 5229.

Collins-Kreiner, N. and Ram, Y., 2020. National tourism strategies during the Covid-19 pandemic. Annals of Tourism Research, [in Press], 103076. https://doi.org/10.1016/j.annals.2020.103076.

EEA-European Environment Agency, 2021. COVID-19 and Europe's environment: impacts of a global pandemic, [online] Available at: <https://www.eea.europa.eu/publications/covid-19-andeurope- s/covid-19-and-europes-environment> [Accessed 10 April 2021].

European Commission, 2020. Report from the commission to the European parliament and the council558 final. [pdf] Available at: <https://loyaltylobby.com/wpcontent/uploads/2020/09/com20200558_allocation_of_slots-1.pdf $>$ [Accessed 3 April 2021].

Gössling, S., Scott, D. and Hall, C.M., 2021. Pandemics, tourism and global change: a rapid assessment of COVID-19. Journal of Sustainable Tourism, 29(1), pp.1-20.

ICIS - Independent Commodity Intelligence Services, 2020. INSIGHT: Different views on pricing, supply and demand split Europe R-PET market, [online] Available at: $<$ https://www.icis.com/explore/resources/news/2020/05/08/10505492/insight-different-views-onpricing-supply-and-demand-split-europe-r-pet-market> [Accessed 10 March 2021].

IEA- International Energy Agency, 2020. Global energy and CO2 emissions in 2020, [online] Available at: <https://www.iea.org/reports/global-energy-review-2020/global-energy-and-co2emissions-in- 2020> [Accessed 5 April 2021].

Il Sole 24 Ore, 2021. Prezzo petrolio, Brent, [online] Available at: $<$ https://mercati.ilsole24ore.com/materie-prime/commodities/petrolio/BRNST.IPE $>$ [Accessed 25 March 2021].

Katircioglu, S.T., Feridun, M. and Kilinc, C., 2014. Estimating tourism-induced energy consumption and $\mathrm{CO} 2$ emissions: The case of Cyprus. Renewable and Sustainable Energy Reviews, 29, pp.634640.

Lokhandwala, S. and Gautam, P., 2020. Indirect impact of COVID-19 on environment: A brief study in Indian context. Environmental Research, 188, Article number: 109807.

Muhammad, S., Long, X. and Salman, M., 2020. COVID-19 pandemic and environmental pollution: A blessing in disguise? Science of The Total Environment, 728, Article number: 138820.

Nagaj, R. and Žuromskaite, B., 2021. Tourism in the Era of Covid-19 and Its Impact on the Environment. Energies, 14(7), Article number: 2000. 
Panzone, L.A., Larcom, S. and She, P.W., 2021. Estimating the impact of the first COVID-19 lockdown on UK food retailers and the restaurant sector. Global Food Security, 28, Article Number: 100495.

Persson-Fischer, U. and Liu, S., 2021. The Impact of a Global Crisis on Areas and Topics of Tourism Research. Sustainability, 13(2), Article Number: 906.

Pham, T.D., Dwyer, L., Su, J. and Ngo, T., 2021. COVID-19 impacts of inbound tourism on Australian economy. Annals of Tourism Research, 88, Article number: 103179.

Sharma, G.D., Thomas, A. and Paul, J., 2021. Reviving tourism industry post-COVID-19: A resiliencebased framework. Tourism Management Perspectives, 37, Article number: 100786.

Silva, A.L.P., Prata, J.C., Walker, T.R., Duarte, A.C., Ouyang, W., Barcelò, D. and Rocha-Santos, T., 2021. Increased plastic pollution due to COVID-19 pandemic: Challenges and recommendations. Chemical Engineering Journal, 405, Article number: 126683.

Škare, M., Soriano, D.R. and Porada-Rochoń, M., 2021. Impact of COVID-19 on the travel and tourism industry. Technological Forecasting and Social Change, 163, Article number: 120469.

Sobieralski, J.B., 2020. COVID-19 and airline employment: Insights from historical uncertainty shocks to the industry. Transportation Research Interdisciplinary Perspectives, 5, Article number: 100123.

UNWTO - United Nations World Tourism Organization, 2021a. 2020: worst year in tourism history with 1 billion fewer international arrivals, [online] Available at: $<$ https://www.unwto.org/news/2020-worst- year-in-tourism-history-with-1-billion-fewerinternational-arrivals> [Accessed 22 March 2021].

UNWTO - United Nations World Tourism Organization, 2021b. International tourism and covid-19, [online] Available at: <https://www.unwto.org/international-tourism-and-covid-19> [Accessed 22 March 2021].

Vanapalli, K.R., Sharma, H.B., Ranjan, V.P., Samal, B., Bhattacharya, J., Dubey, B.K. and Goel, S., 2021. Challenges and strategies for effective plastic waste management during and post COVID-19 pandemic. Science of The Total Environment, 750, Article number: 141514.

Wang, Y., Hong, A., Li, X. and Gao, J., 2020. Marketing innovations during a global crisis: A study of China firms' response to COVID-19. Journal of Business Research, 116, pp.214-220.

Wen, J., Kozak, M., Yang, S. and Liu, F., 2020. "COVID-19: potential effects on Chinese citizens' lifestyle and travel". Tourism Review, 76(1), pp.74-87.

WTTC-World Travel \& Tourism Council, 2020. Economic Impact Reports, [online] Available at: $<$ https://wttc.org/Research/Economic-Impact> [Accessed 10 March 2021].

WWF-World Wildlife Fund, 2018. La plastica dei turisti che soffoca i nostri mari, [online] Available at: $\quad<$ https://www.wwf.it/mediterraneonew/?40780/La-plastica-dei-turisti-che-soffoca-i-nostrimari $>$ [Accessed 5 March 2021].

WWF - World Wildlife Fund, 2019. ITALIA: una guida pratica per uscire dalla crisi della plastica. [pdf] Available at: $<$ https://wwfit.awsassets.panda.org/downloads/fermiamo_inquinamentoplastica_giu2019.pdf> [Accessed 5 March 2021].

Zhang, H., Song, H., Wen, L. and Liu, C., 2021. Forecasting tourism recovery amid COVID-19. Annals of Tourism Research, 87, Article number: 103149. 